\title{
Design, Development and analysis of thermoelectric generator for power generation using exhaust gas of I.C engine
}

\author{
Talape Vishal V*, R.D. Shelke and H.N. Deshpande \\ Heat Power, Savitribai Phule Pune University, Pune India \\ Accepted 15 June 2016, Available online 20 June 2016, Special Issue-5 (June 2016)
}

\begin{abstract}
In recent years, automobile sector technologies are being developed to generate power by using waste heat of hot exhaust gases. In this project no modification of motorcycle exhaust system is needed for producing power using teg. The simple square clamp method eliminates the need of heat exchanger making the construction simple. The power will be derived from vehicle exhaust gas by TEG and further will be stored in battery for the later consumption. If this is project is carried out on large scale applications such as automotive, fuel consumption will be reduced significantly. The sole objective of this project is to generate electricity using thermoelectric generator (TEG), to harvest the thermal energy dissipated by combustion gases. Thus, this technology will reduce the electrical load on alternator in turn reducing the fuel consumption of vehicle. CFD has been used for modeling and simulation of the system.
\end{abstract}

Keywords: Emission, Waste heat from I. C. Engine, Waste heat recovery system for I. C. Engine.

\section{Introduction}

Today, the recent trend is recovery of the energy wasted as heat through the exhaust pipes of I.C engine. It has been one of the major problem in the automotive industry. A great sum of heat would be recovered and the system efficiency of the vehicle would increase substantially, if only a part or even a minor amount of the large waste heat could be recovered and converted into electricity. Effort should be launched for conserving this energy of the exhaust gases through exhaust heat recovery techniques. Such a waste heat recovery techniques would reduce the overall energy requirement and also the impact on global warming. In recent years, because of limited stock of oil supply and increasingly vehicle exhaust gas emission regulations such as Euro 6, new energy technologies such as turbocompounding, thermoelectric generators and the Rankine cycle are being developed and employed to improve fuel efficiency and reduce emission. Automobile using TEG technology converts waste heat from engine exhaust which in turn reduces ICE loads as well as the alternator. Thus it decreases fuel consumption and environmental pollution. The power generation of an exhaust TEG (thermoelectric generator) depends on thermoelectric conversion efficiency.

Thermoelectric power generators offer several distinct advantages over other technologies.
- They are reliable and silent in operation since they have no mechanical moving parts and thus require considerably less maintenance;

- They are simple, compact and safe;

- They have very small size and has low weight;

- They are capable of operating at elevated temperatures;

- They are environmentally friendly.

Z.B. Tang et al. has reported effect of pressure load on performance of TEG. Efficiency of TEG increases as pressure load increases. At high temperature and high load due to insulation on TEG surface power output has increased, whereas without insulation mismatch condition has occurred. Shengqiang Bai et al. has compared 6 different HE designed to trap the heat. He discovered that Serial plate HE has high heat transfer rate but also high pressure drop. Above $80 \mathrm{KPa}$ pressure drop the exhaust system may fail which is undesirable. $\mathrm{X}$. Liu et al. has discussed the suitable location for TEG application where he compared 3 cases. Case1: TEG was located at the end of the exhaust system. Case2:TEG is located between CC and muffler. Case3 TEG is located upstream of CC and muffler. Thus, When TEG is located in between cc and muffler it show uniform flow distribution, higher temperature and less pressure drop. C.Q. Su et al.studied various heat transfer enhancement features are, such as internal structure, material and surface area. He found that Plate-shaped heat exchanger made of brass with

*Corresponding author: Talape Vishal V 
accordion-shaped internal structure improve overall thermal performance of the TEG. Soonseo Park et al. discussed Low temperature generator using Radiators. The extraction of the heat from radiator was done by using heat pipe. High temperature generator using exhaust gas was developed to assess the potential of the combined use of Heat Pipes and commercially available thermoelectric modules for energy recovery of waste heat from the exhaust gases of automotive IC engines. The heat pipes were used as a means of efficiently transferring the heat from the hot exhaust gases to the TEGs. Changwei Liu et al. studied the power generator assembled with TEG modules having installed power of $1 \mathrm{KW}$ at a temperature difference of around $120{ }^{\circ} \mathrm{C}$. TEG system developed had greater efficiency than those of $\mathrm{PV}$ and wind power systems.

\section{Possibility of heat recovery from i.c. engine}

In automobile engines significant amount of heat is dumped into the environment. For example, $35 \%$ of the thermal energy generated from combustion in an automotive engine is released to the environment through the engine exhaust gas and other losses. The amount of such loss, recoverable at least partly or greatly depends on the engine load.

Engine manufacturers have implemented techniques such as enhanced fuel-air mixing, variable valve timing and, turbo-charging to increase thermal efficiency of engine. However, around $60-70 \%$ of the fuel energy is lost in the form of waste heat through the coolant or the exhaust gases. Moreover, increasingly tightened regulations for engine emissions are causing engine manufacturers to limit the temperatures and pressures of combustion thus lowering potential efficiency gains. About more than $60 \%$ of fossil oil has been consumed by transportation, construction and agricultural sectors.

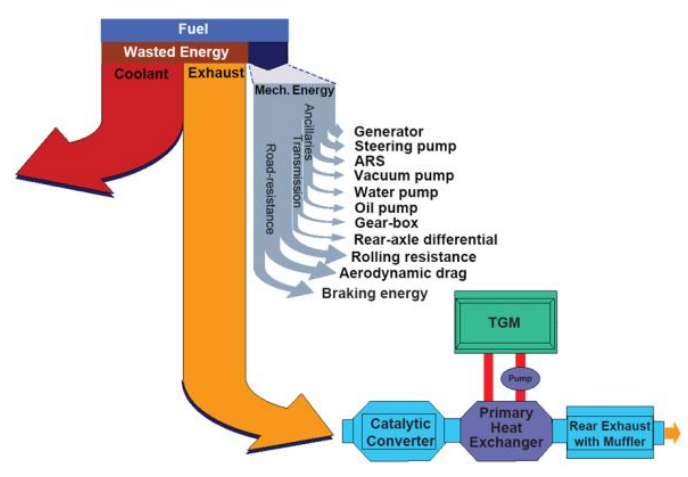

Fig. 1 Waste Heat from Internal Combustion Engine

\section{Basic theory of thermoelectric power generator}

\section{1) Working principle}

The thermoelectric seebeck effect is the direct conversion of temperature differences to electric voltage. A thermoelectric device generates voltage when different temperature is applied on each side. Conversely, when a voltage is applied to it, it creates a temperature difference. At the atomic scale, an applied temperature difference causes charge carriers to move from the hot side to the cold side

\section{Specification of Thermoelectric Module}

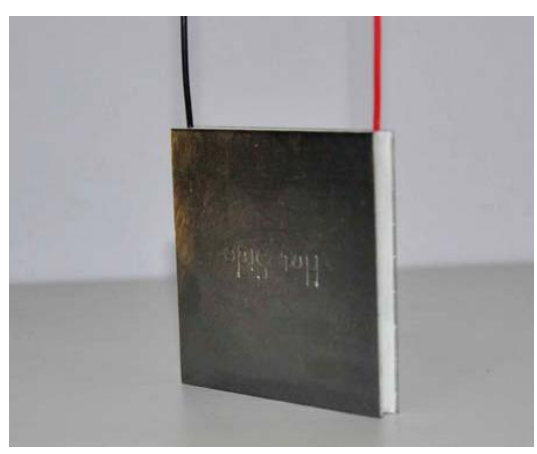

Fig. 2 Thermoelectric module

\begin{tabular}{|c|c|}
\hline Hot Side Temperature $\left({ }^{\circ} \mathrm{C}\right)$ & 300 \\
\hline Cold Side Temperature $\left({ }^{\circ} \mathrm{C}\right)$ & 30 \\
\hline Output voltage $(\mathrm{V})$ & 5.4 \\
\hline Output current $(\mathrm{A})$ & 1.0 \\
\hline Output power $(\mathrm{W})$ & 5.4 \\
\hline
\end{tabular}

The module is Bi-Te based thermoelectric module that can work at the temperature of as high as $330{ }^{\circ} \mathrm{C}$ heat source continuously and up to $400{ }^{\circ} \mathrm{C}$ intermittently. The thermoelectric module will generate DC electricity as long as there exists temperature difference across the module. The more power will be generated as the temperature difference across the TEG module increases, and the efficiency of converting heat energy into electricity will increase therefore. The high thermal conductivity graphite sheet is provided on its both sides of the ceramic plate on module to lower the contact thermal resistance. The graphite sheet can sustain well in extremely high temperature.

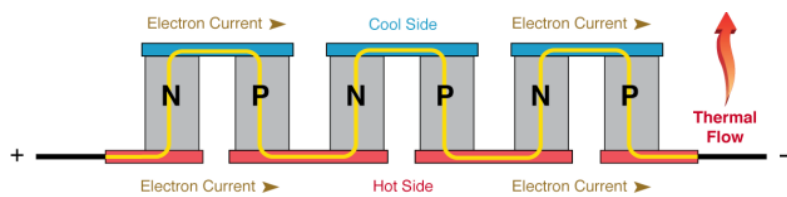

Fig. 3 p-n Junctions of TEG module

The performance of the thermoelectric materials is termed as coefficient of performance as follows,

$\mathrm{Z}_{\mathrm{T}}=\alpha \mathrm{T} 2 / \mathrm{k} \rho$

Where $\rho$ is the electrical resistivity, $\mathrm{k}$ is the thermal conductivity, and $\alpha$ is the Seebeck coefficient.

Using ohms law the load resistance $\left(\mathrm{R}_{\mathrm{L}}\right)$ across TEG modules is given by following formula 
$\mathrm{R}_{\mathrm{L}}=\mathrm{V}_{0} / \mathrm{I}_{0}$

Where $V_{0}$ is the average voltage, $I_{0}$ is the average current.

Power generated $\left(\mathrm{P}_{0}\right)$ by module were calculated using equation

$\mathrm{P}_{0}=\mathrm{V}_{0} \times \mathrm{I}_{0}=\mathrm{R}_{\mathrm{L}} \times \mathrm{I}^{2}$

\section{Heat recovery system i.c engine}

Large quantity of hot flue gases is generated from internal combustion engine etc. If this waste heat could be recovered, a considerable amount of primary fuel could be saved. Parameters to be considered are mass flow rate of exhaust gas and temperature of exhaust gas. The internal combustion engine energy lost in waste gases cannot be fully recovered. However, much of the heat could be minimized and losses be recovered by adopting certain measures. There are various different methods of the exhaust gas heat recovery namely for refrigeration, space heating and power generation. The mass flow rate of exhaust gas is the function of the engine size and speed, hence higher the speed and larger the engine size the exhaust gas heat is larger. So heat recovery system will be beneficial to the large engines as compared to smaller engines. Engine exhaust heat recovery is considered to be one of the most effective means and it has become a research hotspot recently.

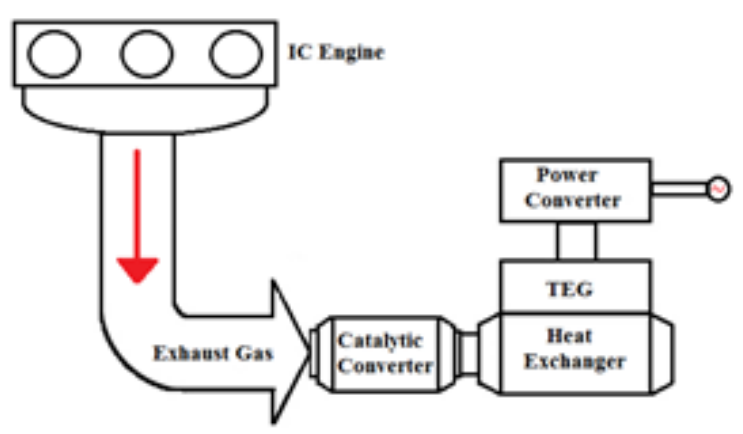

Fig. 4 Location of Thermoelectric Generator

Specification of petrol engine

\begin{tabular}{|c|c|}
\hline Type & Four stroke \\
\hline Cooling system & Air cooled \\
\hline Bore/stroke & $50 \times 50 \mathrm{~mm}$ \\
\hline Comoression ratio & $98.2 \mathrm{cc}$ \\
\hline Piston displacement & $6.6: 1$ \\
\hline Maximum torque & $\begin{array}{c}0.98 \mathrm{~kg}-\mathrm{m} \text { at } \\
5500 \mathrm{rpm}\end{array}$ \\
\hline
\end{tabular}

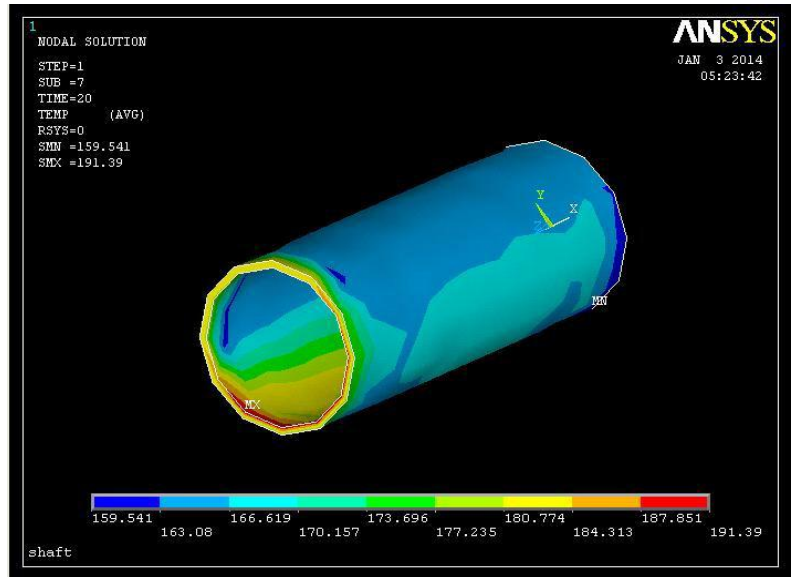

Fig. 5 Temperature of exhaust pipe

\section{Hot source}

The Hot source is the hot waste exhaust gas present in IC engine. An aluminium block is placed on exhaust pipe of 2-wheller right after the end of the cylinder to transmit the heat from the engine to the generator. Aluminium has the high thermal conductivity and high melting point. The reading were taken by using a temperature sensing multi-meter on splendour plus.

Table 1 Temperature of exhaust pipe at given time interval

\begin{tabular}{|c|c|}
\hline Time (mins) & $\begin{array}{c}\text { Exhaust } \\
\text { Temperature }\left({ }^{0} \mathrm{c}\right)\end{array}$ \\
\hline 15 & 145 \\
\hline 30 & 151 \\
\hline 45 & 162 \\
\hline 60 & 175 \\
\hline
\end{tabular}

This exhaust gas temperature is achieved by providing heater in between the aluminium plate as shown in figure

\section{Cold source}

The cold source is given by the air cooling system. Air cooling system is preferred in two wheelers than water cooling system and also water cooling system requires a separate tank and a circulation system. The cold sources temperature is considered as room temperature and it is around $26-30^{\circ} \mathrm{C}$.

The thermoelectric power generating plant composed of four (4) TEG modules. This TEG are connected in series. Such a configuration is used so as to increase $\mathrm{V}$ output to recharge battery. Moreover, this configuration can be altered and made parallel if current is the requirement. 


\section{Development of experimental test rig}

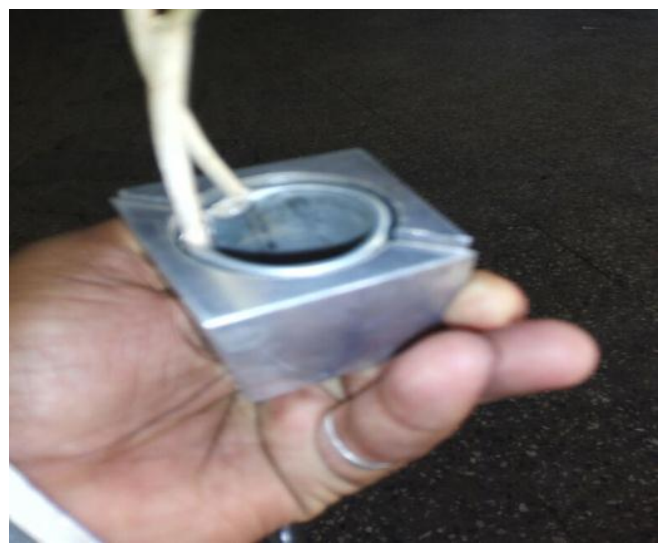

Fig. 6 Aluminium bloc-k with band type heater

The exhaust gases from I.C engine are thrown at a temperature of $300-400{ }^{\circ} \mathrm{C}$ in the atmosphere. Due to this flue gasses, the wall of exhaust pipe heats up to the temperature $150-175{ }^{\circ} \mathrm{C}$. Thus energy recovery from this exhaust outlet is proposed in this study. To quantify and realize the energy generation from these exhaust gases, this prototype is proposed and developed. The prototype can be mounted over the exhaust pipe of 2-wheller for power generation. Following are the some of the design considerations in the model:

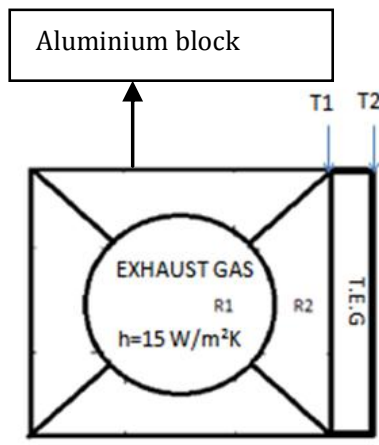

AIR $\mathrm{h}=20 \mathrm{~W} / \mathrm{m}^{2} \mathrm{~K}$

Fig 7 Aluminium block with TEG

1) Prototype is made by drilling hole of $30 \mathrm{~mm}$ (diameter of exhaust pipe) on an aliminium block. And bamd type heater is placed inside the hole for heating. (As shown in fig 6)

2) Generally TEG modules available in market are square in shape. Model block is made square in shape for simplicity in fabrication and assembly. At the time of conclusion the results obtained will be mapped for 4 TEG modules . (As shown in fig 7)

3) The hot side of TEG Module is kept at maximum temperature $\mathrm{T}_{1}$ of $175^{\circ} \mathrm{C}$.

4) The block of model is made of aluminium to give maximum heat dissipation.

5) The readings are taken at the temperature range of $70-175{ }^{\circ} \mathrm{C}$.
6) An electrical band type heater of capacity200W is used for heating to get uniform, gradual heating and to control temperature of model with the help of dimmer stat.

7) This whole assembley is kept inside the duct of dimension $150 * 150 \mathrm{~mm}$ crossection and $1 \mathrm{~m}$ long.

8) Blower is provided at one end to stimulate the vechile in motion i.e the cooling of the cold side will be done by forced air.

A model based on above parameters system was thought and a related prototype was developed. For getting high thermal conductivity model is made using aluminium material. In the model, thermoelectric energy generation system containing TEG Module is mounted on surface of the block in order to get maximum surface area for mounting TEG module.

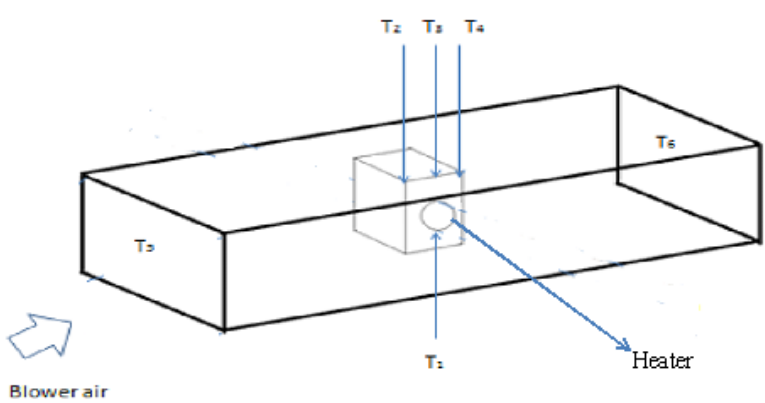

Fig 8 Experimental setup

\section{Experiment Procedure}

The temperature of heater is decided in the range of $70-140^{\circ} \mathrm{C}$ and experimentation was done at increment step of $10^{\circ} \mathrm{C}$ temperature of heat source starts at $70^{\circ} \mathrm{C}$ The voltage and current at each temperature difference were noted.

Table 2 power output for given temperature difference

\begin{tabular}{|c|c|c|c|c|c|c|}
\hline $\begin{array}{c}\text { Sr. } \\
\text { no }\end{array}$ & $\begin{array}{c}\text { Heat } \\
\text { Source } \\
\left({ }^{\circ} \mathrm{C}\right)\end{array}$ & $\begin{array}{c}\text { Heat } \\
\text { Sink } \\
\left({ }^{\circ} \mathrm{C}\right)\end{array}$ & $\begin{array}{c}\text { Difference } \\
\Delta \mathrm{T}(\mathrm{K})\end{array}$ & $\begin{array}{c}\mathrm{V}_{\mathrm{o}} \\
(\text { Volts })\end{array}$ & $\begin{array}{c}\mathrm{I}_{0} \\
(\mathrm{Amp})\end{array}$ & $\begin{array}{c}\text { Power } \\
\text { Output } \\
(\text { Watts })\end{array}$ \\
\hline 1. & 70 & 28 & 42 & 1.27 & 0.45 & 0.57 \\
\hline 2. & 80 & 29 & 51 & 1.67 & 0.55 & 0.91 \\
\hline 3. & 90 & 34 & 56 & 2.07 & 0.62 & 1.28 \\
\hline 4. & 100 & 38 & 62 & 2.47 & 0.65 & 1.6 \\
\hline 5. & 110 & 42 & 68 & 2.87 & 0.68 & 1.95 \\
\hline 5. & 120 & 47 & 73 & 3.6 & 0.71 & 2.54 \\
\hline 6. & 130 & 80 & 80 & 3.93 & 0.72 & 2.85 \\
\hline 7. & 140 & 85 & 85 & 4.47 & 0.77 & 3.42 \\
\hline
\end{tabular}

It represents that power output from the system increases with increase in temperature difference. Equation 6 shows higher temperature differences $(\Delta \mathrm{T})$ must be applied in order to get higher power output $\left(\mathrm{P}_{\mathrm{o}}\right)$. Conclusion 


\section{Conclusion}

The results obtained from the experimental data as seen in Table 2 shows that electrical energy can be obtained by means of TEG modules. It is seen that the power and efficiency of the system increases with respect to increasing values of temperature differences applied on the TEG modules. At the end of experiment, it is seen that this method is suitable for the generation of electrical energy in small quantity. More energy can be harvested and period of cost recovery can be improved by making multistage modules or by large width module manufacturing and by finding high performance heat insulation material.

\section{References}

Z.B. Tang, Y.D.Deng, C.Q.Su, W.W.Shuai, C.J.Xie. (2015), A research on thermoelectric generator electrical performance under temperature mismatch conditions for automotive waste heat recovery system, Case studies in Thermal Engineering Vol. 5 143-150.
ShengqiangBai, HongliangLu, TingWu, XianglinYin, XunShi, Lidong Chen. (2014) Numerical and experimental analysis for exhaust heat exchangers in automobile thermoelectric generators, Case studies in Thermal Engineering Vol. 499 112.

X. Liu, Y.D.Deng, S.Chen, W.S.Wang, Y.Xu,C.Q.Su. (2014), A case study on compatibility of automotive exhaust thermoelectric generation system, catalytic converter and muffler, Case studies in Thermal Engineering Vol. 2 62-66.

C.Q. Su n, W.S.Wang, X.Liu, Y.D.Deng. (2014), Simulation and experimental study on thermal optimization of heat exchanger for automotive exhaust based thermoelectric generator, Case studies in Thermal Engineering Vol. 4 8591.

Soonseo Park, JunghoYoo, Sungkyu Cho, Hyunju Lee, and Shiho Kim. (2009), Low and high Temperature Dual Thermoelectric Generation Waste Heat Recovery System for Light-Duty Vehicles, DEER Conference, August 5

Changwei Liu, Pingyun Chen, Kewen Li. (2014), A 1 KW Thermoelectric Generator for Low-temperature Geothermal Resources, Geothermal Reservoir Engineering Stanford California. 